\title{
AERONAUTICAL SITUATIONAL AWARENESS - AIRPORT SURFACE
}

\author{
Vladimir M. Linetsky, Vantage Partners, LCC, Cleveland, Ohio \\ William D. Ivancic and Karl R. Vaden, NASA Glenn Research Center, Cleveland, Ohio
}

\begin{abstract}
This paper advocates for a specific design approach, based on simple principals, yet addresses challenges faced by the system engineers when designing complex data and information infrastructure. The document provides guidance for breaking out various work elements in the overall network architecture design, so that communication systems are conceived and effectively realized regardless of their location, size and local specifics. Although targeted at the Global Airspace System (GAS) and National Airspace System (NAS), this framework can be applied to any network-centric architecture.
\end{abstract}

\section{Introduction}

The air transportation community is continually looking to improve the safety and efficiency of the Global Airspace System (GAS). The community consists of national and international government entities, airlines, equipment suppliers and manufacturers, and a variety of service providers.

In order to improve efficiency and maintain safety of GAS, two major programs have been created. They are the Next Generation Air Transportation System (NextGen) in the United States and Single European Sky ATM Research (SESAR) in Europe. NextGen [1] [2] is an Air Traffic Control (ATC) modernization program, which uses sophisticated technologies and new flight procedures to reduce flight delays, flight times and aircraft fuel burn/emissions. SESAR [3] is a collaborative project to completely overhaul European airspace and its air traffic management (ATM) system.

Note: This document was created with hyperlinks to ease reading. To go back to where you were after clicking a hyperlink, try the following in PDF readers: Alt +left arrow, or command +left arrow. In Preview, the default PDF reader on Macs, the equivalent is command-[ (open square bracket).
NASA's Airspace Operations and Safety Program (AOSP) researches and creates technologies to help NextGen to fulfill its promise. AOSP works with the Federal Aviation Administration (FAA), industry and academic partners to conceive and develop NextGen technologies. The Safe Autonomous Systems Operations (SASO) and Shadow Mode Assessment Using Realistic Technologies for the National Airspace System (SMART-NAS) projects are part of AOSP. SASO identifies and develops the maximum possible autonomous capabilities. The SMART-NAS Project will develop an air traffic management simulation capability to explore integration of alternative concepts, technologies and architectures within the NAS.

\section{Purpose}

In today"s world of ever-increasing information sharing and importance of data mining and exchange, numerous information systems and technologies are being proposed to effectively direct complex data flows, manage accurate intelligence gathering, and ensure timely decision-making based on collected information.

This paper advocates for a specific design approach, based on simple principals, yet addresses challenges faced by the system engineers when designing complex data and information infrastructure. The document provides guidance for identifying the key work elements in the overall network architecture design. Although targeted at the GAS and NAS, this framework can be utilized with any network-centric architecture that deal with situational awareness. The stakeholders, information type, information requirements, and how to efficiently move that information from point $\mathrm{A}$ to point $\mathrm{B}$ are the key components of this framework.

\section{Design Methodology}

The proposed framework, as illustrated in Figure 1 consists of three major stakeholders (horizontal rela- 
tionships) and three categories (vertical dependencies)

1. The stakeholders are: the airlines, government Air Traffic Management (ATM) organizations and Airport Operations. The three categories that define functions of the proposed methodology are: What, Who and How.

In general, What identifies the main problem a proposed system has to address. A clearly identified problem determines the main purpose of the system of interest. What to be or what not to be; are both important questions.

Who identifies the major stakeholders interested in such a system. Who also establishes the hierarchy and relationships between stakeholders in terms of information sharing, inter-category relationships (horizontal links) information flow (direction) and its requirements. The stakeholders are those who determine whether the system satisfies their needs. They are the ones that provide a Concept of Operations (CONOPS) They are the ones that need to determine major key performance indicators (KPI) which MUST be identified at this stage.

How category establishes common data definitions and requirements, processes and procedures necessary to accomplish the task of effectively and efficiently transporting data from a data producer to a data consumer(s) During this stage it is important to clearly identify data producers and associated consumers, their locations, characteristics of the data and the best way to transform data into information ${ }^{2}$. Finally, How identifies the technologies and means to deliver the information. This stage is further divided into two subcategories: information definition and implementation definition.

Information Definition This subcategory deals with identification of what data and information is flowing within the system, its characteristics,

\footnotetext{
${ }^{1}$ One should note the terminology used in defining vertical and horizontal process flows. Vertical flow is called dependences and horizontal ones are called relationships. The reason behind the choice of words is that the vertical flow is sequential in nature where each subsequent stage depends on the information input (deliverables) from the preceding phase. In contrast, the horizontal relationships are independent of each other, which may exist, or may not exist at all.

${ }^{2}$ Data and Information are slightly different. Data is generally raw and unprocessed whereas information is processed data condensed into a concise and meaningful product.
}

requirements and direction. During this phase, a number of information sources (producers) and destinations (consumers) are identified. This is the stage where the intelligence gathering and information analysis are defined. Finally, data security requirements and sharing principles between the major stakeholders are determined.

Implementation Definition The Implementation Definition phase utilizes the results of the Information Definition phase to determine the right technologies and means to deliver and exchange data. This is the stage where the most optimal ways of data-flow and exchange are identified. After the appropriate Network Modeling is performed, the final Information System Design is implemented and tested.

This network-centric communication-system design methodology enables the project team to effectively assign roles and responsibilities to ensure the delivery of timely and accurate project results. Stakeholders' information needs and requirements are identified and information characteristics and requirements are defined. From this information, the appropriate wireless technologies are identified as are the information security requirements. The next step is modeling and designing the system based on the technologies identified. The system is deployed, tested and demonstrated. Finally, validation and approval of the final product by the major stakeholders is attained. 


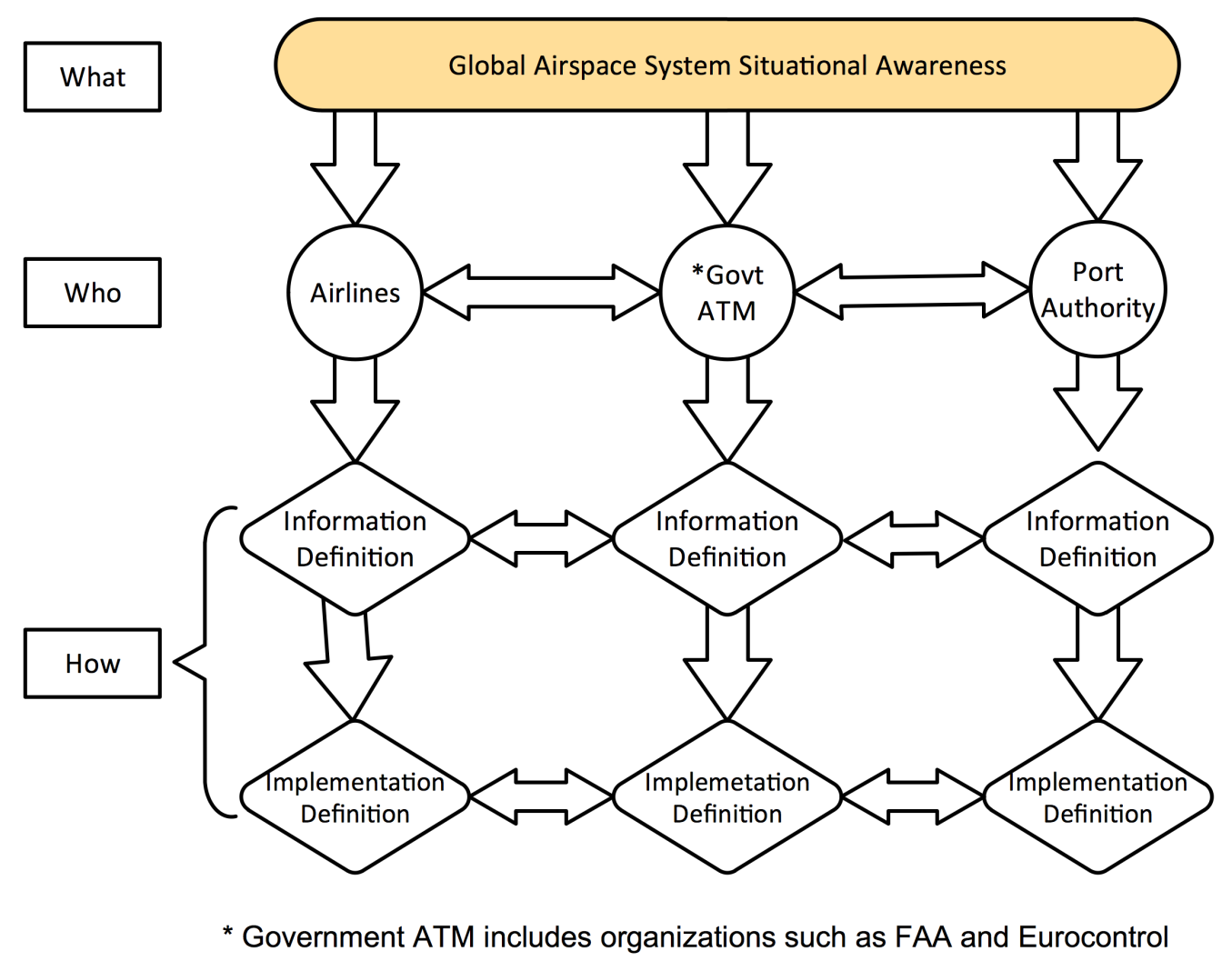

Figure 1. Design Methodology

\section{Goals}

It is evident that the newer, more modern communication and information infrastructures are required in order to accommodate an increasingly complex nature of the National and Global Airspace Systems. The goal is to develop an architecture that enables and provides Aeronautical Situational Awareness - particularly as it relates to the airport surface. In addition, it is necessary to think in terms of the Global Deployment and Global Scalability for items such as radio access transparency, network traversal (particularly with regards to aircraft roaming), and information access.

The remaining portion of the paper applies the previously mentioned design methodology to develop an architecture that enables Aeronautical Situational Awareness with regard to the airport surface. Global Deployment and Scalability for all communication system components is essential to avoid developing the system that is limited to the locally deployed assets $^{3}$ - see Appendix: Terminology

Figure 2 illustrates the framework for designing a network centric communication architecture that provides situational awareness for an aeronautical environment with emphasis on the airport surface. Here, the stakeholders determine what information and its characteristics is going to be carried by the system. In turn, this would determine what type of technologies are needed to transport that Information through the network.

\footnotetext{
${ }^{3}$ Locally deployed assets are items such as radar, sensors, surveillance video cameras and fire and rescue. Assets such as aircraft roam between airports on a global scale.
} 


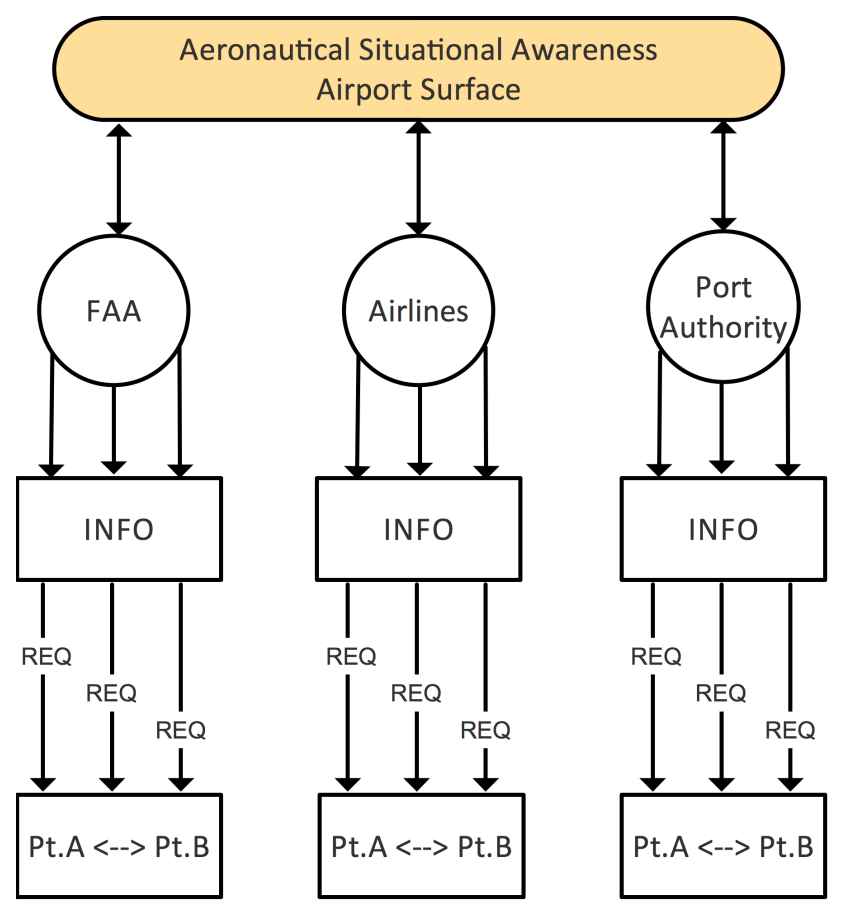

Figure 2. Aeronautical Situational Awareness Airport Surface

\section{Stakeholders (Who)}

There are three main stakeholders: the Civil Aviation Air-Traffic Management Authority (e.g., FAA and European Organisation for the Safety of Air Navigation (EUROCONTROL)), Airlines, and Port Authority. Each of these entities needs information to maintain a safe and efficient environment - in our case airport surface environment. Also, they might need access to the same information in additions to their own proprietary information. Each of these entities needs to exchange information with each other: some of which is open to all and some of which has limited distribution (i.e., proprietary information). The relationsip between these stakeholders will determine security and sharing mechanism of the proposed network system.

\section{Information Definition}

Information is the key to situational awareness. There are many types of information flowing through the system and each of the types of information has particular requirements attached to it. For example, voice for command and control requires high priority and low delay, whereas something like passenger lists and catering information is noncritical and delay tolerant. The following subsections describe information requirements and information types. The characteristics of the different information types needs to be identified in order to provide an optimized network centric communication system.

\section{Information Requirements}

There is a multitude of information requirements. The following is a list of the most common ones that are present in an aeronautical network-centric environment:

- Delay sensitive (e.g. voice, command and control)

- Delay tolerant (e.g. file transfers)

- Bandwidth sensitive (bandwidth hogs)

- Mission-critical (priority)

- Authenticity - the ability to prove that some particular information came from one and only one source and is unaltered.

- Confidentiality - the ability to only allow those consumers with proper credentials to comprehend the meaning of the information. Note, others may receive or see the data, but are unable to comprehend the information contained within the received data.

\section{Information Types}

There are numerous types of information related to the airport surface communications and operations. Most of these require relatively low bandwidth by nature or design. Resource monopolizers tend to be real-time video streams (likely associated with video surveillance) and large files, such as software or operating system updates, or updating of onboard entertainment services. The following are some of the major information types:

- Radar

- Video Surveillance

- Vehicle positioning information

- Weather: may be in many forms - from high resolution 3D graphics to simple text

- Software and Database Loading including updated onboard entertainment systems

- Aircraft Communications Addressing and Reporting System (ACARS) messages: short messages between aircraft and ground stations 
- Air Traffic Control messages used to request or provide clearances.

- Aeronautical Operational Control

- Airline Administrative Control

- Mechanical Systems Data

- System Wide Information Management (SWIM) data [4] - see FAA:SWIM

- Food and Catering

\section{Information Producers}

This section will identify a number of information producers found within the airport environment. This is only a subset of the various information generators that exist at an airport (ex. gate, tarmac, runway and airport grounds). This should not be considered an all-encompassing list. In addition, when possible, the stakeholder associated with the product is identified.

Vehicle performance and maintenance : It is highly desirable for the organizations to obtain vehicle performance and maintenance information. This information is often used to schedule routine maintenance as well as predicting the onset of failures and performing preventative maintenance during a time of choice rather than a time of need. Airlines will want to download engine performance data from their aircraft and likely will want this information to remain confidential to those outside the organization as well as many within the organization. Likewise, the port authority may wish to have performance information related to their snow removal equipment, lawnmowers, trucks, and other vehicles that they may have to maintain.

Aircraft flight operations : Flight operations data information may include: passenger lists, catering needs, deicing needs, and perhaps on-demand video streaming from an aircraft to the first responders for instances involving medical emergency or security (passenger disruptions).

Pilots : A Pilot Report (PIREP) is a report of actual weather conditions encountered by an aircraft in flight. It is highly conceivable that such PIREPs may be consolidated and retransmitted upon landing.

Various airlines may also have their pilots provide a summary of the flight to the airline operations center. Such information is likely to be considered confidential.
Airline flight operations : Airline flight operations may include information such as: baggage, catering, fuel, crew lists, passenger lists, downloading and uploading of credit card information, onboard entertainment system movies, and updating of software. Much if this information is likely confidential.

Sensors : On the grounds of an airport there are a variety of sensors, each with diverse bandwidth requirements. The sensors may be owned and maintained by different organizations. For example the radars maintained by the FAA whereas surveillance video is the responsibility of airport operations. Other sensors include: weather, lighting, wind shear, wind direction, runway conditions, etc. By far the sensors that require the greatest bandwidth are video monitoring systems.

Vehicle Tracking : It is highly desirable for the port authority and tower controllers to be able to track individual maintenance vehicles. Currently vehicles can be monitored via ground-based radar (surface radar). But that does not provide any information identifying the exact vehicle including vehicle type, or who may be operating the vehicle. Note, ground radar is still necessary for tracking vehicles that are not equipped with tracking hardware.

Port Authority: Airport Rescue and Fire Fighters : In emergency situations involving airport rescue and fire fighters, is highly desirable to track assets as well as individuals. Airport rescue and firefighters may also produce video that needs to be sent to the proper authorities.

FAA: SWIM : Is both a producer and consumer of information. Some of the current SWIM information[4] related to airport surface include:

- Aeronautical Information Management (AIM) Federal Notice to Airmen (NOTAM) System (FNS) is a notice containing information concerning the establishment, condition, or change in any component (facility, service, procedure, or hazard within the National Airspace System).

- AIM Special Activity Airspace (SAA): Provides Airport reference and configuration data, including: definitions and schedule information for SAA, Temporary Flight Restriction (TFR), procedure En Route Area Navigation (RNAV)/Required Navigation Performance (RNP) data, and obstacles. 
- Integrated Terminal Weather System (ITWS) provides a variety of weather information in graphic and textual forms, such as windshear and microburst predictions, storm cell and lightning information, and terminal area winds aloft. SWIM Flight Data Publication Service (SFDPS) provides a variety of En Route flight data, such as flight plans, beacon codes, and handoff status. SFDPS will also disseminate data regarding airspaces, such as Sector configuration data, route status, SAA status, and altimeter settings.

- SWIM Terminal Data Distribution System (STDDS) provides surface movement data Airport Surface Detection System - Model X (ASDE-X), Runway Visual Range (RVR), and a variety of departure event data.

\section{Information Consumers}

There are many consumers of information, albeit not nearly as many consumer as producers. Often, multiple entities desire to consume the same information. In some cases, when multiple entities wish to receive the same information, it is sent to both simultaneously. In other instances, it is sent to one entity, which then retransmits to the others. This is often the case with SWIM data. The following is a small list of some of the major data consumers:

- Airline Operations Centers

- Airport Operations

- FAA Tower Controllers

- FAA SWIM

- Pilots and air crew

- Airport and Local Security

- Medical and First Responders including airport rescue and fire fighters.

\section{Implementation Definition}

During the implementation definition phase, the various stakeholders' Concept of Operations (CONOPS) must be considered along with the following system requirements:

1) Seamless ${ }^{4}$ Global Access,

2) Seamless Billing,

3) Manageable Service Agreements (e.g. Qualityof-Service (QoS)),

\footnotetext{
${ }^{4}$ In the above requirements, "seamless" implies machine-tomachine communications without human intervention. A single identity is the key to enabling seamless operations.
}

4) Scalable Seamless Management, and

5) Seamless Roaming.

New technologies may also be considered for deployment; but, in order for such technologies to be viable, they MUST meet all the requirements of what we coin the "Able List":

"Able" List

- Adaptable,

- Affordable,

- Deployable,

- Evolvable,

- Global(able),

- Maintainable,

- Manageable,

- Reliable,

- Scalable, and

- Securable.

The "Able List" is describe in detail in "Securing the Global Airspace System via Identity-Based Security[5]".

One example of a CONOPS relates to how the airlines and air traffic controllers want the pilots to operate regarding use of SWIM technology. What is the span of control? The pilots or traffic controller do not want any confusion over who is in control. Does the pilot need to be utilizing the electronic flight bag while moving within the terminal area? Or, will it be adequate to receive and transmit data and update systems while parked at the gate? The former would require Aircraft Access to SWIM (AAtS) to be delivered via some wireless technology such as:

- Worldwide Interoperability for Microwave Access (WiMAX),

- Aeronautical Mobile Airport Communications System (AeroMACS),

- Long Term Evolution (LTE) or

- some other wireless system.

The latter may simply require connecting to the airline's terminal Wi-Fi system. The former may require additional antennas placed on the aircraft as a well as a global deployment of radio network access, global QoS management, Internet access and seamless billing. The latter may require none of these.

LTE has much of this infrastructure in place globally. WiMAX and AeroMACS are already being deployed in local settings. Large operators are deploying LTE because it is compatible in many aspects 
with existing $2 \mathrm{G} / 3 \mathrm{G}$ infrastructure - particularly with regards to roaming. Many operators are deploying both technologies, focusing different market segments using WiMAX for fixed and nomadic deployments and LTE for global roaming [6].

\section{Wireless Technologies}

Some of the of various wireless technologies available include but are not limited to: Wi-Fi, WiMAX (802.16), AeroMACS, point-to-point microwave systems. Their salient characteristics are listed below. It is important to note the new wireless technologies are constantly being developed and that the frequency spectrum allocations are continually changing to adapt to these new technologies [7].

$\mathrm{Wi}-\mathrm{Fi}$ is the generic term for Institute of Electrical and Electronics Engineers (IEEE) 802.11 wireless protocols. Wi-Fi technologies are directed at wireless Local Area Network (LAN) Media Access Control and Physical Layer specification. The 802.11 protocols continue to evolve with new improved technologies coming out every few years making 802.11 protocol extremely attractive. There are a number of additional standards that fall under the 802.11 umbrella .

- 802.11a specifies a physical layer that operates in the $5 \mathrm{GHz}$ band in the US - since expanded to additional frequencies - uses Orthogonal Frequency-Division Multiplexing (OFDM) and operates at data speed up to $54 \mathrm{Mbps}$.

- 802.11b is capable of data speed to 11 Mbps. Automatically falls back to $5.5,2$, or $1 \mathrm{Mbps}$ from 11 Mbps max depending on the channel characteristics. $802.11 \mathrm{~b}$ operates in the frequency range of $2.400 \mathrm{GHz}$ to $2.4835 \mathrm{GHz}$ using 3 non-overlaping channels.

- 802.11e enhances the 802.11a and $802.11 \mathrm{~b}$ Message Authentication Code (MAC) layer with a coordinated Time-Division Multiple Access (TDMA) construct, and adds error-correcting mechanisms for delay-sensitive applications such as voice and video.

- 802.11g operates in the $2.4 \mathrm{GHz}$ band, in a fashion that permits interoperation with $802.11 \mathrm{~b}$ devices. 802.11g Uses OFDM modulation enabling up to 54 megabits per second (Mbps) data-rates, with fall-back speeds that include the "b" speeds.
- 802.11n operates in the $2.4 \mathrm{GHz}$ or $5 \mathrm{GHz}$ frequency bands and uses up to four spatial streams at a channel width of $40 \mathrm{MHz}$ along (standardized Multiple Input, Multiple Output (MIMO) technologies) with 64 Quadrature Amplitude Modulation (QAM), frame aggregation, and security improvements to increase data rates up to $450 \mathrm{Mbps}$.

- 802.11ac operates in the $5 \mathrm{GHz}$ frequency band and uses up to eight spatial streams at a channel width of up to 80 or even $160 \mathrm{MHz}$ (standardized MIMO technologies) with 256 QAM enabling a multi-station Wireless Local Area Network (WLAN) throughput of at least $1.3 \mathrm{Gbps}$ and a single link throughput of at least $500 \mathrm{Mbps}$.

WiMAX [8][9] refers to implementations of the IEEE 802.16 family of wireless broadband standards certified by the WiMAX forum. The original 802.16 standard - Fixed WiMAX was published in December of 2001. It specified transmissions in the frequency range 10 - $66 \mathrm{GHz}$. IEEE 802.16d allowed lower frequencies in the range 2 to $11 \mathrm{GHz}$ [10]. Based on 802.16e-2005 standard, the Mobile WiMAX was introduced as a mobile revision of the original protocol, which was designed as a point-to-multipoint technology where a Base Station provides an access to the multiple users - Subscribers ${ }^{5}$. It also serves as a basis for the future WiMAX reincarnations, such as $802.16 \mathrm{~m}$. The network speed and range of the technology make it suitable for various applications:

- Providing portable and mobile connectivity across cities and countries,

- Providing a wireless alternative to the cable and DSL broadband access,

- Providing data, VoIP and IPTV services (triple play), and

- Smart grids and metering.

The most often used WiMAX flavor is the Time Division Duplex (TDD) version, where a channel capacity is split between downlink (base station to client direction) and uplink (client to base station direction ) with a dominating downlink direction. There is no uniform, globally allocated spectrum for WiMAX. In an effort to promote standardization and

\footnotetext{
${ }^{5}$ Use of WiMAX technology for video surveillance where the traffic is mainly generated from the subscriber station side of the connection, may not be the best choice because the WiMAX system is mainly a downlink bound technology.
} 
reduce cost, WiMAX Forum has published licensed spectrum profiles for $2.3,2.5$ and $3.5 \mathrm{GHz}$ frequencies. WiMAX uses bandwidths of 5, 10, and $20 \mathrm{MHz}$ in the United States and 3.5, 7 and $14 \mathrm{MHz}$ in Europe. In addition, unlicensed Unlicensed National Information Infrastructure (UNII) frequencies in the $5 \mathrm{GHz}$ band can be used with WiMAX system. It supports data rates up to $120 \mathrm{Mbps}$ at ranges of up to 30 mile. Although desirable, line-of-sight between the client and the base station is not required. WiMAX network can operate in near-line-of-sight conditions.

AeroMACS is a subset or "profile" of WiMAX standard (IEEE 802.16e) and operates in the protected aviation spectrum band from $5091 \mathrm{MHz}$ to $5150 \mathrm{MHz}$. AeroMACS is targeted for transmission of safety and regularity of flight data for both fixed and mobile applications on the airport surface. AeroMACS uses 11 channels of $5 \mathrm{MHz}$ bandwidth allocation.

\section{A. Frequency Allocations and Transmit Power Considerations}

The IEEE 802.16 WiMAX standard allows data transmission using multiple broadband frequency ranges. The original 802.16a standard specified transmissions in the range $10-66 \mathrm{GHz}$. IEEE 802.16d allowed lower frequencies in the range 2 to 11 $\mathrm{GHz}$ [10]. These lower frequencies suffer less from attenuation and therefore they provide improved range and better coverage within buildings. Different bands are available for WiMAX applications in different parts of the world. The frequencies commonly used are 3.5 and $5.8 \mathrm{GHz}$ for $802.16 \mathrm{~d}$ and $2.3,2.5$ and $3.5 \mathrm{GHz}$ for $802.16 \mathrm{e}$ but the use depends upon the countries.
There are two values to be considered in assessing transmit power: Transmitter Power Output (TPO) and EIRP. TPO is a measure of the power being delivered to the transmitting antenna and EIRP is the result of adding any antenna gain.

Effective Isotropic Radiated Power is also called the Equivalent Isotropic Radiated Power. It is the amount of power that a theoretical isotropic antenna (which evenly distributes power in all directions) would emit to produce the peak power density observed in the direction of maximum antenna gain. EIRP can take into account the losses in transmission line and connectors and includes the gain of the antenna. The EIRP allows comparisons between different emitters regardless of type, size or form. From the EIRP and with knowledge of a real antenna's gain, it is possible to calculate real power and field strength values. The EIRP is used to estimate the service area of the transmitter, and to coordinate transmitters on the same frequency so that their coverage areas do not overlap. EIRP is normally restricted to minimize interference to services on similar frequencies.

Tables I-IV show the TPO and EIRP for the various FCC rules and wireless technlogies [13][9][14]. Note, in table IV the vast discrepancy in transmit power for WiMAX versus AeroMACS. AeroMACS is sharing its frequency band with pre-existing services. The AeroMACS service must not interfere with other users in the same band. In particular, the allocation of the 5091-5150 MHz band to the Earth-to-space fixed-satellite service (FSS), limited to feeder links of non-geostationary satellite systems in the mobilesatellite service (MSS). It is utilized by the Globalstar network, which restricts the output power levels that will be allowed for AeroMACS networks - see Table IV.[11][15] 
Table I. Federal Communications Commission (FCC) 2.400 to $2.4835 \mathrm{GHz}$ and 5.725 to $5.875 \mathrm{GHz}$ industrial, scientific, and medical radio (ISM) Band Rules (Point-to-Multipoint) Maximum $=+36 \mathrm{dbm}$ (4 Watts)

\begin{tabular}{|c|c|c|}
$\begin{array}{c}\text { Maximum Power from } \\
\text { Iternational Radiator } * \mathbf{1}\end{array}$ & $\begin{array}{c}\text { Maximum Antenna } \\
\text { Gain }(\mathbf{d B i})\end{array}$ & EIRP $(\mathbf{d B m}) * \mathbf{2}$ \\
\hline $30 \mathrm{dBm}$ or $1 \mathrm{Watt}$ & 6 & 36 \\
\hline $27 \mathrm{dBm}$ or $500 \mathrm{~mW}$ & 9 & 36 \\
\hline $24 \mathrm{dBm}$ or $250 \mathrm{~mW}$ & 12 & 36 \\
\hline $21 \mathrm{dBm}$ or $125 \mathrm{~m} 1$ & 15 & 36 \\
\hline $18 \mathrm{dBm}$ or $63 \mathrm{~mW}$ & 18 & 36 \\
\hline $15 \mathrm{dBm}$ or $32 \mathrm{~mW}$ & 21 & 36 \\
\hline $12 \mathrm{dBm}$ or $16 \mathrm{~mW}$ & 24 & 36 \\
\hline
\end{tabular}

Table II. FCC 2.400 to 2.4835 GHz ISM Band Rules (Point-to-Point) Maximum = See FCC Special Rule *3

\begin{tabular}{|c|c|c|}
\hline $\begin{array}{c}\text { Maximum Power from } \\
\text { Iternational Radiator } * \mathbf{1}\end{array}$ & $\begin{array}{c}\text { Maximum Antenna } \\
\text { Gain }(\mathbf{d B i})\end{array}$ & EIRP $(\mathbf{d B m}) * \mathbf{2}$ \\
\hline $30 \mathrm{dBm}$ or $1 \mathrm{Watt}$ & 6 & 36 \\
\hline $29 \mathrm{dBm}$ or $800 \mathrm{~mW}$ & 9 & 38 \\
\hline $28 \mathrm{dBm}$ or $630 \mathrm{~mW}$ & 12 & 40 \\
\hline $27 \mathrm{dBm}$ or $500 \mathrm{~mW}$ & 15 & 42 \\
\hline $26 \mathrm{dBm}$ or $400 \mathrm{~mW}$ & 18 & 44 \\
\hline $25 \mathrm{dBm}$ or $316 \mathrm{~mW}$ & 21 & 46 \\
\hline $24 \mathrm{dBm}$ or $250 \mathrm{~mW}$ & 24 & 48 \\
\hline $23 \mathrm{dBm}$ or $200 \mathrm{~mW}$ & 27 & 50 \\
\hline $22 \mathrm{dBm}$ or $160 \mathrm{~mW}$ & 30 & 52 \\
\hline
\end{tabular}

*1 The FCC terminology of Intentional Radiator is the transmitter power of the wireless equipment, such as a wireless access point, router or bridge.

*2 Effective Isotropic Radiated Power (EIRP) is terminology for the total RF power radiated by the antenna.

*3 In the 2.400 to $2.4835 \mathrm{GHz}$ band you can increase the antenna gain to get an EIRP above $36 \mathrm{dBm}$ but for every $3 \mathrm{dBi}$ increase of antenna gain you must reduce the transmit power by $1 \mathrm{dBm}$.

*4 In the 5.725 to $5.875 \mathrm{GHz}$ band the rule is less restrictive.

The maximum EIRP allowed is $53 \mathrm{dBm}$ ( $30 \mathrm{dBm}$ plus up to $23 \mathrm{dBi}$ of antenna gain)

When reading tables I-IV, note the terminology. Point-to-Multipoint is base station to subscriber station (downlink). Point-to-Point can be considered fixed subscriber station to base station (uplink). Here, the location of the base station is known. Thus the fixed subscriber station can use a larger antenna to focus energy while still keeping interference to an acceptable level. Mobile subscriber stations are moving and therefore are assumed to be incapable of accurately pointing large antennas. Thus, mobile stations are restricted in the amount of power they may transmit - particularly relative to fixed subscriber stations. 
Table III. FCC 5 UNII GHz Bands and Rules

\begin{tabular}{|c|c|c|c|c|c|}
\hline Band & $\begin{array}{l}\text { Frequency } \\
\text { (GHz) }\end{array}$ & $\begin{array}{c}\text { Point-to- } \\
\text { Point Max. } \\
\text { Intentional } \\
\text { Radiator } \\
\text { Power } * 1\end{array}$ & $\begin{array}{l}\text { Point-to- } \\
\text { Point } \\
\text { Max. } \\
\text { EIRP } * 2\end{array}$ & $\begin{array}{c}\text { Point-to- } \\
\text { MultiPoint } \\
\text { Intentional } \\
\text { Radiator } \\
\text { Power } * 1\end{array}$ & $\begin{array}{c}\text { Point-to- } \\
\text { MultiPoint } \\
\text { Max. } \\
\text { EIRP } * 2\end{array}$ \\
\hline $\begin{array}{c}\text { UNII-2 } \\
\text { (Middle) }\end{array}$ & $5.25-5.35$ & $\begin{array}{l}200 \mathrm{~mW} \\
23 \mathrm{dBm}\end{array}$ & $\begin{array}{l}800 \mathrm{~mW} \\
29 \mathrm{dBm}\end{array}$ & $\begin{array}{c}200 \mathrm{~mW} \\
23 \mathrm{dBm} * 4\end{array}$ & $\begin{array}{l}800 \mathrm{~mW} \\
29 \mathrm{dBm}\end{array}$ \\
\hline $\begin{array}{c}\text { UNII-2 } \\
\text { Extended }\end{array}$ & $5.470-5.725$ & $\begin{array}{l}200 \mathrm{~mW} \\
23 \mathrm{dBm}\end{array}$ & $\begin{array}{l}800 \mathrm{~mW} \\
29 \mathrm{dBm}\end{array}$ & $\begin{array}{c}200 \mathrm{~mW} \\
23 \mathrm{dBm} * 4\end{array}$ & $\begin{array}{l}800 \mathrm{~mW} \\
29 \mathrm{dBm}\end{array}$ \\
\hline $\begin{array}{l}\text { UNII-3 } \\
\text { (Upper) }\end{array}$ & $5.725-5.825$ & $\begin{array}{c}30 \mathrm{dBm} \text { plus } \\
\text { Antenna to } \\
23 \mathrm{dBi} * 3\end{array}$ & $\begin{array}{c}200 \text { watts } \\
53 \mathrm{dBm}\end{array}$ & $\begin{array}{c}800 \mathrm{~mW} \\
29 \mathrm{dBm} * 4\end{array}$ & $\begin{array}{l}3200 \mathrm{~mW} \\
35 \mathrm{dBm}\end{array}$ \\
\hline
\end{tabular}

*1 The FCC terminology of Intentional Radiator is the transmitter power of the wireless equipment, such as a wireless access point, router or bridge.

*2 Equivalent Isotropically Radiated Power (EIRP) is terminology for the total RF power radiated by the antenna.

*3 Fixed point-to-point in the UNII-3 band may utilize directional antennas up to $23 \mathrm{dBi}$ gain without any corresponding reduction of the Intentional Radiator's RF output power. If antennas higher than $23 \mathrm{dBi}$ gain are utilized, a reduction of $1 \mathrm{~dB}$ is required for every $1 \mathrm{~dB}$ increase in the antenna gain above $23 \mathrm{dBi}$.

*4 The FCC point to multipoint rule is the maximum power from the intentional radiator + maximum antenna gain of $6 \mathrm{dBi}$. For every $1 \mathrm{~dB}$ gain over $6 \mathrm{~dB}$, the power of the intentional radiator must be reduced by $1 \mathrm{~dB}$.

Table IV. EIRP for IEEE 802.16 Technologies

\begin{tabular}{|c|c|c|c|}
\multicolumn{5}{|c|}{ IEEE 802.16 } \\
\hline & $\begin{array}{c}* 1 \text { Base Station } \\
\text { EIRP }\end{array}$ & $\begin{array}{c}* 1 \text { Base Station } \\
\text { EIRP }\end{array}$ & Comments \\
\hline WiMAX & $44 \mathrm{dBm} / 25 \mathrm{MHz}$ \\
$3.65-3.7 \mathrm{GHz}$ & $30 \mathrm{dBm} / \mathrm{MHz}$ & $\begin{array}{c}30 \mathrm{dBm} / 25 \mathrm{MHz} \\
16 \mathrm{dBm} / \mathrm{MHz}\end{array}$ & $\begin{array}{c}\text { For Mobile and Portable } \\
\text { stations, the maximum } \\
\text { Power Spectral Density is } \\
40 \mathrm{~mW} / \mathrm{MHz} \text { EIRP }\end{array}$ \\
\hline $\begin{array}{c}\text { AeroMACS } * 3 \\
5.091-5.15 \mathrm{GHz}\end{array}$ & $39.4 \mathrm{dBm}$ & $30 \mathrm{dBm} / 5 \mathrm{Mhz} * 2$ & elev angles up to $1.5 \mathrm{deg}$ \\
\hline & $39.4 \mathrm{dBm}$ linearly decr (in dB) to $24.4 \mathrm{dBm}$ & $30 \mathrm{dBm} / 5 \mathrm{Mhz} * 2$ & elev angles from 1.5 to $7.5 \mathrm{deg}$ \\
\hline & $24.4 \mathrm{dBm}$ linearly decr (in dB) to $19.4 \mathrm{dBm}$ & $30 \mathrm{dBm} / 5 \mathrm{Mhz} * 2$ & elev angles from7.5 to $27.5 \mathrm{deg}$ \\
\hline & $19.4 \mathrm{dBm}$ linearly decr (in dB) to $11.4 \mathrm{dBm}$ & $30 \mathrm{dBm} / 5 \mathrm{Mhz} * 2$ & elev angles from 27.5 to $90 \mathrm{deg}$ \\
\hline
\end{tabular}

*1 If a station sector contains multiple transmit antennas on the same frequency (e.g., MIMO), the specified power limit is the sum of the power from each antenna.

*2 This is the total subscriber EIRP based on full occupancy of transmit subcarriers for a $5 \mathrm{MHz}$ bandwidth [11]. It is not clear that these numbers are correct as they don't directly match FCC $3.65-3.7 \mathrm{GHz}$ rules.

*3 For Mobile and Portable stations, the Max output power $200 \mathrm{~mW} / 5 \mathrm{MHz}(+23 \mathrm{dBm} / 5 \mathrm{MHz})$ which implies the same EIRP requirements as WiMAX: 40/mW/MHz (16dBm/MHz) [12] 


\section{Summary}

The proposed framework tries to address the problem of designing and building an effective data infrastructure and information system in such a way that it can be conceived and deployed regardless of its geolocation, size and local specifics. In other words, this framework is abstract enough to be applied anywhere, an effective data and information system is required.

During implementation definition phase, the various stakeholders' CONOPS must be considered along with the system requirements. New technologies may also be considered for deployment; but, in order for such technologies to be viable, they MUST meet all the requirements of the "Able List".

\section{References}

[1] FAA, "Nextgen," Http://www.faa.gov/nextgen/, 2015.

[2] H. Swenson, R. Barhydt, and M. Landis, "Next generation air transportation system (ngats) air traffic management (atm)-airspace project," Reference Material, External Release Version, NASA, 2006.

[3] Eurocontron, "Sesar joint undertaking," Http://www.sesarju.eu/, 2015.

[4] Swim data products, 2016. [Online]. Available: http : / / www . faa . gov / nextgen / programs / swim / products/.

[5] W. D. Ivancic, "Securing the global airspace system via identity-based security," in Digital Avionics Systems Conference (DASC), 2015 IEEE/AIAA 34th, IEEE, 2015, 4B3-1.

[6] L. Korowajczuk, "Broadband network design best practices: Myths and truths," 2013. [Online]. Available: http://www.wimaxforum.org/LiteratureRetrieve. aspx?ID=177983.

[7] Opening up of $3.65 \mathrm{ghz}$ band has begun, 2015. [Online]. Available: http://www. wimaxforum.org/ press - release/opening - up - of - 3- 65 - ghz- band - has begun.

[8] Wimax-technology for broadband wireless access, August. [Online]. Available: http://etutorials . org / Networking / wimax + technology + broadband + wireless + access / WiMAX - Technology + for + Broadband+Wireless+Access/.
[9] Technical notes and frequently asked questions about wireless data networking, 2016. [Online]. Available: http://www.connect802.com/tech_notes. htm.

[10] W. Forum, "Requirements and recommendations for wimax forum mobility profiles," no. WMF-T21001-R010v01, 2005. [Online]. Available: http : / / www. wimaxforum .org/sites/wimaxforum . org/files/ technical_document / 2009/08 / WMF - T21 - 001 R010v01\% 20Rel\% 201.0\% 20Mobility \% 20Profile\% 20Requirements.pdf.

[11] J. D. Wilson, "Modeling c-band co-channel interference from aeromacs omni-directional antennas to mobile satellite service feeder uplinks," 2011.

[12] Y. Sumiya, N. Kanada, K. Morioka, N. Yonemoto, A. Kohmura, S. Futatsumori, M. Shioji, and T. Tomita, "Modification in the session of emission in aeromacs draft sarps," ICAO, Tech. Rep. ACP-WGS05/WP07, 2014. [Online]. Available: https : / / www . google . com / url $? \mathrm{sa}=\mathrm{t} \& \mathrm{rct}=\mathrm{j} \& \mathrm{q}=\& \mathrm{esrc}=\mathrm{s} \&$ source $=$ web $\&$ $\mathrm{cd}=1 \& \mathrm{cad}=$ rja $\&$ uact $=8 \&$ ved $=0$ ahUKEwjZ d - c9KLLAhUG2T4KHaZHBxoQFggdMAA \& url $=$ http $\% 3 \mathrm{~A} \% 2 \mathrm{~F} \% 2 \mathrm{Fwww}$. icao . int $\%$ 2Fsafety $\%$ 2Facp \% 2Facpwgf \% 2Facp - wg s - $5 \%$ 2Fwp07\% 2520 - \%2520modification \% $2520 \mathrm{in} \%$ 2520the \% 2520session \% 2520of \% 2520emission \% 2520in \% 2520aeromacs \% 2520draft \% 2520sarps _ 20140714 . docx \& usg = AFQjCNFhoaWdUMFM5qTjFMHuwAICHT-q5A.

[13] Fcc rules and regulations, 2016. [Online]. Available: http : / / www . air802 . com / fcc - rules - and regulations.html.

[14] ICOA, "Mss interference analysis for aeromacs," 2015. [Online]. Available: http :// www . icao . int / safety/acp/ACPWGF/acp\%20s\%20test/AeroMACS\% 20MSS\%20interference\%202015-03-30.docx.

[15] J. D. Wilson and R. J. Kerczewski, "Interference analysis for an aeronautical mobile airport communications system," in Aerospace Conference, 2011 IEEE, IEEE, 2011, pp. 1-8. 


\section{Appendix I: Terminology}

Aeronautical Situational Awareness is the generic term for situational awareness provided by a network centric architecture for aeronautical applications.

Mobility Terms (Taken from WiMAX and cellular industry)

- Fixed: No mobility. System is always within the same antenna coverage.

- Nomadic: Mobility within the same antenna coverage. No handovers.

- Mobile: The system moves between antenna coverages and handovers occur between base stations (BS) at the radio link.

- Roaming: Mobility is between networks such as an aircraft moving from one airport to another. Handovers occur at the network layer (e.g. mobile-ip).

\section{Appendix II: Acronyms List}

\section{ACARS Aircraft Communications Addressing} and Reporting System

AAtS Aircraft Access to SWIM

AeroMACS Aeronautical Mobile Airport Communications System

AIM Aeronautical Information Management

AOSP Airspace Operations and Safety Program

ASDE-X Airport Surface Detection System Model X

ATC Air Traffic Control

ATM Air Traffic Management

CONOPS Concept of Operations

EIRP Effective Isotropic Radiated Power

EUROCONTROL European Organisation for the Safety of Air Navigation

FAA Federal Aviation Administration

FCC Federal Communications Commission

FSS fixed-satellite service

FNS Federal NOTAM System

GAS Global Airspace System

IEEE Institute of Electrical and Electronics Engineers

ITWS Integrated Terminal Weather System

KPI key performance indicators

ISM industrial, scientific, and medical radio
LAN Local Area Network

LTE Long Term Evolution

MAC Message Authentication Code

MIMO Multiple Input, Multiple Output

MSS mobile-satellite service

NAS National Airspace System

NextGen Next Generation Air Transportation System

NOTAM Notice to Airmen

OFDM Orthogonal Frequency-Division Multiplexing

PIREP Pilot Report

QAM Quadrature Amplitude Modulation

QoS Quality-of-Service

RNAV En Route Area Navigation

RNP Required Navigation Performance

RVR Runway Visual Range

SAA Special Activity Airspace

SASO Safe Autonomous Systems Operations

SESAR Single European Sky ATM Research

SFDPS SWIM Flight Data Publication Service

SMART-NAS Shadow Mode Assessment Using

Realistic Technologies for the National Airspace System

STDDS SWIM Terminal Data Distribution System

SWIM System Wide Information Management

TDD Time Division Duplex

TDMA Time-Division Multiple Access

TFR Temporary Flight Restriction

TPO Transmitter Power Output

UNII Unlicensed National Information Infrastructure

WiMAX Worldwide Interoperability for Microwave Access

WLAN Wireless Local Area Network 